\title{
La retradicionalización de los roles de género en la maternidad transnacional: el caso de mujeres peruanas en Santiago de Chile ${ }^{*}$
}

\author{
The retraditionalization of gender roles in transnational motherhood: \\ the case of Peruvian women in Santiago de Chile \\ Camila León Gin ${ }^{*}$ \\ Universidad Alberto Hurtado, Santiago, Chile
}

Recibido: 30 de abril de 2012. Aprobado: 18 septiembre de 2013.

\begin{abstract}
Resumen
Este artículo reconstruye las prácticas y redes de mujeres migrantes y también indaga en las transformaciones e implicancias de la migración en la familia de origen y destino. Esto desde la perspectiva de las mujeres, con el fin de ahondar con mayor interés en las implicancias que tiene la migración en los roles de género que se ejercen en la maternidad de mujeres peruanas que viven en Santiago de Chile. El método de investigación consistió en la construcción de relatos de vida a cuatro mujeres peruanas ${ }^{1}$. Como resultado, es posible esbozar una exacerbación de los roles tradicionales de género en la maternidad, luego de la migración, como también el uso de redes no familiares en el país de origen y destino. Las familias transnacionales exigen una reacomodación permanente de las relaciones de género y generacionales en cuanto a los vínculos económicos, afectivos y de poder dentro del grupo doméstico, tanto en los lugares de origen como de destino. Tales articulaciones están fuertemente condicionadas por el género.
\end{abstract}

Palabras claves: roles de género, familia transnacional, maternidad transnacional

\footnotetext{
El presente artículo forma parte del Proyecto Fondecyt № 1110414: "La construcción del espacio y del lugar en contextos de migración transnacional. Espacios públicos y privados de la migración peruana en Chile".

Universidad Alberto Hurtado. Correo electrónico: cami.leongin@gmail.com

Revisar “Tabla Resumen de Casos” en Anexos.
} 


\begin{abstract}
This article reconstructs female migrant networks and their practices, and explores the changes and implications of migration on the family of origin and family of destination. This article focuses on the perspective of Peruvian women living in Santiago, Chile, in order to deepen with greater interest the implications that migration has on gender roles, specifically exemplified through the exercise of maternity. The investigation methodology consisted in the construction of narratives of the lives of four Peruvian women. As a result, it is possible to show an exacerbation of traditional gender roles through motherhood after migration, as well as show the use of non-family networks in the country of origin and the country destination. In terms of the economic, affective and power bonds within the domestic group, transnational families require constant rearrangement of gender and generational roles in their places of origin and places of destination. Such bonds are strongly conditioned by gender.
\end{abstract}

Keywords: gender roles, transnational family, transnational motherhood

\title{
Introducción
}

En general, los enfoques y teorías de las migraciones se han dedicado a describir el carácter racional de la decisión de migrar, la búsqueda de bienestar contenida en el proyecto migratorio, o la tesis ampliamente compartida acerca de la migración femenina motivada básicamente por la reagrupación familiar (Mahler y Pessar, 2006). Esta última, muy profundizada por los estudios que indagaron a las mujeres migrantes, privilegiando su inscripción en los movimientos de población como mujeres trabajadoras. Si bien se trató de un afán por agregar y mezclar las mujeres en las migraciones internacionales (Hondagneu-Sotelo, 2007), ha tenido como consecuencia un énfasis en el carácter laboral de la migración femenina y en la invisibilización de otros aspectos históricamente desatendidos, como las tareas desarrolladas en el ámbito reproductivo (Tapia, 2010).

Las contribuciones teóricas más recientes, que tienen como foco de interés las relaciones de género y las migraciones, han hecho hincapié en la necesidad de incorporar el enfoque de género. Se trata no solo de agregar una variable más del análisis, sino de agregar el género como principio organizador de la movilidad humana, como una categoría explicativa, entendiendo la migración internacional como un proceso generizado (Tapia, 2010). 
El género como enfoque o perspectiva se entiende como una forma de decodificar el significado que las culturas y la sociedad otorgan a la diferencia de sexos, y de comprender las complejas conexiones entre varias formas de interacción humana (Lamas, 2003a, p. 330). Asimismo, supone considerar a los sujetos, la organización social y sus interacciones como relaciones de poder, de cuyo resultado, hombres y mujeres pueden tener una experiencia diferente en base a lo que se espera de ellos de acuerdo al momento histórico y al lugar específico. Es decir, permite "delimitar con mayor claridad y precisión cómo la diferencia cobra la dimensión de desigualdad” (Lamas, 2003b, p. 116).

Los estudios se han centrado en la forma de la vida de las mujeres migrantes en Chile. Sin embargo, no hay mayor conocimiento sobre los efectos de la migración en el país de origen, cómo continúa la vida familiar en Perú desde que la mujer migra, y cómo se reconfigura con las salidas/entradas de ella y otros integrantes, así como tampoco se ha estudiado la forma en que conviven la familia de origen con la familia que se crea en el país de destino. Se comenzará con la premisa de que las familias transnacionales se mantienen por las prácticas y vínculos que se conservan cotidianamente por los integrantes de la familia que se encuentra separada. Ahora bien, una pregunta es ¿qué hace la mujer para mantener estos vínculos y prácticas, y cómo cambia esto con la migración? Una segunda pregunta es saber ¿qué sucede con la familia luego de la migración de la mujer?

Aun cuando se tiende a decir que la consecuencia más importante de la migración en la vida de las mujeres es la independencia económica y autonomía que otorga el trabajo en otro país, en la investigación se plantea que podría suceder exactamente lo contrario: el trabajo y migración las hace más dependientes de su familia en el país de origen y, por consiguiente, estaríamos frente a una situación donde no es el orden de género ni la migración los que se adaptan o modifican, sino que es la familia la que se reacomoda al contexto que enfrenta luego de la emigración de la mujer.

\section{La perspectiva de género en el marco migratorio}

La visibilización de la relevancia del género en los estudios migratorios, ha sido consecuencia de una efectiva movilización generalizada de mujeres en el mundo. Respecto a América Latina y el Caribe, para el 2005 se estimó que más del 13\% de los migrantes del mundo había nacido en la región, es decir, unas 25 millones de personas, de las cuales un $50 \%$ eran mujeres (Rico, 2006). De hecho, hoy es posible afirmar que uno de los rasgos más característicos de la emigración latinoamericana, es la feminización de los flujos internacionales (Martínez, 2003). Coherente con lo anterior se advierte el aumento del 
rol económico de la migración femenina, en tanto las mujeres lo hacen para trabajar más allá de las fronteras con un proyecto migratorio familiar o autónomo (OIM, 2006; ONU, 2006).

Chile es un país que se ha posicionado como un destino frecuente para inmigrantes de la región (Cano, Soffia y Martínez, 2009). Actualmente, la población extranjera crece más aprisa que la nacional, y se proyecta que los tratados internacionales y la profundización de la inserción económica internacional refuerce la atracción de migrantes, convirtiendo a Chile en un receptor cada vez más importante dentro de la región (Cacopardo y Maguid, 2007, p. 234; Doña y Levinson, 2004).

Llama la atención que las migrantes de origen fronterizo han llegado hasta la capital de Chile para ejercer fundamentalmente como empleadas domésticas en los barrios de clase alta de la ciudad de Santiago. Se trata casi siempre de mujeres en edad productiva y reproductiva, que han recorrido largas distancias desde el norte y centro del Perú para trabajar en el servicio doméstico (Stefoni, 2007; 2009). A pesar de la lejanía, la migración sur-sur alberga mayores posibilidades de retorno o de circularidad de la migración (Tapia, 2010) y, por tanto, el ejercicio de la maternidad transnacional puede ser menos "problemática" que en el caso de la migración de larga distancia.

Respecto a la inserción laboral en el lugar de destino, los estudios muestran que las mujeres andinas realizan preferentemente actividades de cuidado, ya sea trabajo doméstico o atención a niños y adultos mayores, y que sus condiciones laborales varían mucho dependiendo de su situación migratoria (Stefoni, 2007), del acceso a un mercado laboral más formalizado, del tiempo de migración y de su contexto familiar. De ahí que muchas investigaciones se han centrado en las contradicciones de las experiencias migratorias de las mujeres, mostrando que si bien estas viven procesos de movilidad económica y de transformación en las relaciones de género, también experimentan desvalorización social en sus trabajos.

En la misma dirección, se pone en evidencia cómo una inserción laboral precaria viene acompañada de grandes dificultades respecto a cómo organizar el cuidado de las personas dependientes en los países de destino, y esto complica tanto los procesos de reunificación familiar como la organización de estos una vez que las mujeres han llevado a sus familias con ellas (Herrera, 2011, pp. 89-90). Esta situación ha permitido la proliferación de estudios que vinculan el parentesco a la unidad doméstica, es el caso de la visibilización de prácticas que unen a las familias mediante el envío de remesas. Como 
también, investigaciones que se centran en el uso de nuevas tecnologías de comunicación (Rivas y Gonzálvez, 2009).

Es el caso de familias unidas no solo por las remesas, sino por la conexión que entregan las comunicaciones vía internet, telefonía fija y móvil (Reist y Riaño, 2008). Asimismo, llaman la atención los trabajos referidos a la integración de la economía capitalista en el marco de la globalización y su impacto en la reproducción social (Mora, 2008). En este ámbito, la crítica feminista ha avanzando hacia la consideración de la familia como un espacio de poder, donde los lugares que ocupan hombres y mujeres no son iguales ni equitativos (Tapia, 2010).

Por otra parte, las investigaciones centradas en las prácticas transnacionales de cuidado muestran que estas cadenas transnacionales se tejen en una red social y cultural construida sobre jerarquías de género, sociales y generacionales, que moldean la forma en que ocurren los arreglos de cuidado dentro de las familias y que se vinculan a prácticas muy arraigadas en las historias familiares. Se ha notado que las prácticas transnacionales de cuidado coexisten con discursos culpabilizadores hacia - o desde- las migrantes. En consecuencia, se produce una relación contradictoria entre el mantenimiento de prácticas y vínculos transnacionales, por parte de las familias migrantes, y una representación de la experiencia migratoria de separación como un problema de desintegración familiar.

\section{La familia transnacional}

Los términos familia "multilocal" o "transcontinental" son a menudo utilizados para designar el mismo tipo de realidad familiar: la familia transnacional (Glick-Schiller, Basch y Blanc-Szanton, 1992; Guarnizo, 1997; Faist, 2000). La "familia transnacional" es definida por Le Gall (2005, p. 30) como aquella unidad familiar caracterizada por la dispersión de sus miembros en distintos países, debido a la migración de uno o más de sus integrantes. Sin embargo, los movimientos migratorios desde siempre han configurado familias "transnacionales", en el sentido de "internacionales", al implicar la separación física y geográfica de sus miembros durante prolongados períodos, por lo que no estaríamos ante un fenómeno nuevo.

Lo que sí constituye una novedad con respecto a épocas anteriores, es la posibilidad material que ofrecen los avances en las nuevas tecnologías, los sistemas de transportes y las comunicaciones de permitir formas de relaciones sociales que faciliten a las unidades familiares "transnacionales" seguir actuando como una "familia", en el sentido 
de tomar decisiones y discutir los temas importantes que atañen a sus miembros (Vertovec, 2004).

Por ello, en este trabajo se utiliza el término "familia transnacional", en el sentido de unidad que concibe y gestiona su bienestar desde una dimensión colectiva y con una interiorización de los vínculos entre sus miembros (Bryceson y Vuorela, 2002). Por consiguiente, no todas las familias separadas geográficamente van a constituir "familias transnacionales" de manera inevitable o van a mantenerse como tales a lo largo del tiempo. La evolución, extensión, alcance y efectos de las prácticas que se dan en su seno dependerán de la interacción de múltiples factores que tienen que ver con las relaciones de género, la clase social, la edad, el contexto social, político y económico, etc. (Guarnizo, Portes y Haller, 2003). Aproximarse a la familia en su vivir transnacional, exige estudiar las formas y significados que los hogares usan para gestionar la reproducción social, para crear espacios familiares y vínculos materiales, de afecto y de cuidado en un contexto en el que las conexiones están geográficamente dispersas (Bryceson y Vuorela, 2002; Levitt y Glick-Schiller, 2004; Parella, 2007).

\section{Los roles de género y la maternidad transnacional}

Un aspecto fundamental para el análisis de los ajustes transnacionales que tienen que ver con los roles de género, es considerar los proyectos migratorios concebidos en sí mismos desde una perspectiva de género. Los condicionantes de género intervienen en los proyectos migratorios, tanto de los varones como de las mujeres, ya que ambos son sujetos "generizados" (Hondagneu-Sotelo, 2000). Es necesario aproximarse a la maternidad y género, teniendo en cuenta las relaciones desiguales de poder que se dan en el seno de la familia, así como también la asignación diferenciada de roles en los procesos de construcción de las identidades y en la reproducción del bienestar de sus miembros (Moore, 1999; Herrera, 2004, 2005).

Si bien puede afirmarse que la migración supone una renegociación de los roles de género y provoca una reestructuración de las asimetrías de género, de acuerdo con Rosas (2010, p. 246), se trata de modificaciones y cambios que no necesariamente "anulan la desigualdad". Es decir, la migración conlleva la potencialidad de cambio en las relaciones de género, sin que sea posible a priori establecer su ocurrencia, ni cuáles van a ser las características de este cambio, su sentido o sus resultados - si dichas asimetrías van a reducirse o, por el contrario, pueden verse incluso reforzadas- (Gregorio, 1998; Ariza, 2000; Oso, 2007). 
De esta manera, la migración como un proceso sociocultural, repercute en las dinámicas familiares de cada uno de sus miembros, y reconoce las relaciones de poder de género y también de parentesco, así como la división sexual del trabajo y el cuidado en hombres y en mujeres igualmente en un contexto transnacional (Gonzálvez, 2007). De esta forma, la perspectiva de género restituye el lugar que ocupan las mujeres en la migración, visibiliza el lugar que ocupan los hombres en los cuidados, y muestra que la migración es un proceso generizado (Gonzálvez, 2007, p. 347).

Así, el vínculo género-parentesco en tanto construcción social y eje de desigualdad social es determinante para explicar la dimensión transnacional de las migraciones, entre ellas, las familias vinculadas a la migración y las redes migratorias a partir de los cuidados transnacionales. Ahora bien, el género y parentesco son dos ejes de desigualdad tan poderosos anclados en dicotomías público/privado, producción/reproducción, culpa/liberación, que se reproducen a través de las prácticas de cuidado transnacionales (Gonzálvez, 2007).

Las "redes migratorias" constituyen la base analítica para explicar tanto la génesis como el mantenimiento de las migraciones internacionales, así como para abordar los vínculos transnacionales (Massey et al., 1993). Una de las consecuencias de la globalización es que los individuos organizan sus vidas en un espacio migratorio cada vez más global, que une las áreas de origen con las de destino (Parella, 2007, pp. 159-160). Las redes sociales conectan a migrantes y no migrantes a través del tiempo y del espacio, y son de vital importancia en el proceso migratorio. Mediante las redes se forman nexos permanentes entre los emigrantes y sus familias, estableciendo espacios plurilocales (con el permanente intercambio y circulación de bienes materiales, culturales y simbólicos) que dan sentido y estimulan el proceso migratorio (López y Acosta, 2003).

\section{Metodología}

Dada la pregunta central de la investigación, fue pertinente utilizar una metodología capaz de captar los significados que la mujer entrevistada le otorga a su experiencia personal de la migración, como también la forma en que ellas construyen sus historias individuales, familiares y el contexto situacional en el que se encontraban. Además, incorporar la dimensión temporal (desde la salida del país de la mujer hasta la actualidad), y también comprender el significado que se le otorga a su propia experiencia, así como indagar la forma en que las personas construyen la situación familiar y contextual desde que migran. 
El paradigma constructivista/interpretativo entrega respuestas a estas problemáticas, en la medida que permite comprender la experiencia humana a través del desarrollarlo de la interacción de los significados de experiencias individuales. En este caso, la premisa es que los patrones culturales del país de origen, como también el orden de género, son ambos realidades subjetivas, con múltiples significados y construcciones realizados por los participantes. Por lo que se reconoce que el acercamiento a las participantes es a través de una relación, en la que intervienen valores, patrones culturales distintos, diferentes concepciones de la experiencia migratoria y, por ende, sesgos y co-construcción de la experiencia humana.

El método de acercamiento a dicha realidad es una lógica inductiva interpretativa, que da cuenta del contexto, ya sea la situación migratoria, económica y social, como también histórico de las entrevistadas. La pertinencia del método es que, justamente, se investiga a las personas en situaciones cotidianas/naturales, intentando darle sentido a situaciones del pasado y actuales, rearmando historias familiares y también buscando el significado a sus decisiones. Es por eso que el método interpretativo es un proceso interactivo forjado por la historia personal, biografía, género, clase social, raza, etnicidad (Denzin y Lincoln, 2005, p. 28).

Para ello, se construyeron relatos de vida a cuatro mujeres peruanas ${ }^{2}$ a través de la realización de tres entrevistas a cada una, produciendo un total de 12 entrevistas en profundidad en tres distintas etapas y momentos. Una primera etapa consistió en una entrevista general en el lugar de trabajo respecto a la familia en Perú y Chile, donde se indagó principalmente en la familia en el país de origen y destino. En la segunda etapa se realizó una entrevista profunda en el hogar de la mujer y se indagó específicamente en la maternidad. Finalmente, se realizó una tercera entrevista, recogiendo aspectos relevantes revisados anteriormente, como también rearmando su relato. El trabajo de campo se realizó desde junio a diciembre del 2012.

Los criterios de selección utilizados fueron los siguientes: que las mujeres fueran peruanas, que trabajaran en Santiago de Chile por más de dos años y que tuvieran parte de su familia en Perú. Se intentó que cada caso permitiera indagar sobre situaciones recurrentes de la migración peruana en Chile (teniendo presente de antemano que cada caso no es representativo de la experiencia de las mujeres peruanas en Chile, ni tampoco que cada una de ellas es un caso nacional peruano): un caso de una mujer que trabaja puertas adentro, con tres años en Chile y con sus dos hijos y pareja en Perú; un segundo caso de

2 Revisar “Tabla Resumen de Casos” en Anexos. 
una mujer que trabaja por día en casa, lleva 11 años en Chile, y con sus dos hijos, nieta y marido en Chile. El tercer caso es una mujer que cuida un anciano, lleva cinco años en Chile y tiene un hijo de cuatro años en este país y otro de 17 años en Perú. Finalmente, una mujer que trabaja independiente en una peluquería, lleva 12 años en Chile y tiene un hijo de 27 años en Perú y su hija y nieta en Santiago de Chile.

\section{Resultados}

A continuación, se estructurarán los resultados de la investigación de acuerdo a las implicancias y transformaciones de la migración en los roles de género en la maternidad transnacional. Dado que el argumento central del artículo explica que en las entrevistadas se observa una profundización de los roles tradicionales de género en lo relacionado con la maternidad, se explicará en tres aspectos la retradicionalización: 1) producción/ reproducción, 2) la culpa/liberación por el cuidado, y 3) las relaciones de poder en la maternidad.

\section{La producción y reproducción}

En primer lugar, respecto a los cambios que produce la migración en las tareas de producción y reproducción, todas las entrevistadas trabajaban en Perú originalmente, sin embargo, su motivación para emigrar es, principalmente, la mala situación económica, por lo que ven en Santiago de Chile un lugar donde pueden conseguir un avance económico para sus familias. Gonzálvez (2007) argumenta que las mujeres en destino tienen probabilidades de generar transformaciones sobre los significados de género y parentesco que producen desigualdad, cambiando para ello determinadas prácticas sociales (sexuales, nuevas parejas, etc.).

Ahora bien, todas las mujeres entrevistadas llegan a Chile y se esfuerzan por conseguir un trabajo que les permita ahorrar y enviar remesas a Perú, de ahí que inviertan la mayor parte de su tiempo en el trabajo. Entendiendo, entonces, que luego de la migración, las mujeres no solo consiguen trabajo que requiere inversión de tiempo y energías para ahorrar dinero, sino que también se encargan del cuidado y crianza de los hijos, a pesar de la distancia. 
Además, se puede visualizar en el discurso de las entrevistadas, que no aparece el padre ni la pareja actual en términos de padres o trabajadores, como agentes relevantes en la migración. Las mujeres que tienen a sus hijos en Perú, como también las que los tienen en Chile, expresan que diaria o semanalmente conversan con sus hijos, les ayudan con las tareas del colegio, los cuidan si están enfermos, se preocupan de ellos en todos los aspectos de sus vidas. Ya sea a distancia o no, la mujer se hace cargo de la crianza. Ahora bien, aún cuando el hombre o padre se haga cargo, esto no aparece en el discurso, ni para criticar o reclamar su paternidad.

Lo anterior es relevante, pues nuevamente se vuelve a los roles tradicionales de padre y madre. Un caso importante es el de una entrevistada que tiene a toda su familia en Chile y su marido, padre de sus dos hijos, según lo interpretado es muy presente, por ejemplo: ella es asesora del hogar y su jornada termina después de las 20:00 hrs, en cambio su marido llega de regreso del trabajo a las 18:30 hrs. Ella explica que él llega y se hace cargo de las tareas de sus hijos y ve a su nieta hasta que ella llega. La entrevistada reconoce que es un padre muy presente y le ayuda bastante. Sin embargo, en ningún momento aparece como determinante o relevante en la crianza, como tampoco lo fue cuando él estuvo en Perú por tres años con los niños, mientras ella estaba en Chile. Ella se adjudica la culpa y responsabilidad de lo que le sucede a sus hijos.

Otro ejemplo, es el padre de los hijos de una de las entrevistadas (su ex pareja), él vive en Perú y visita a sus hijos eventualmente, sin embargo, no aparece en el discurso de la mujer con un rol importante en el cuidado. De hecho, sus hijos viven con los abuelos.

En el siguiente párrafo podemos ver un ejemplo de una abuela cuidadora:

Prácticamente les cocina... su ropita para llevarlos al colegio, prácticamente es como una mamá, y mi papá ya está jubilado ya, está en su casa, recibe su pensión, con parte de lo que yo le mando para los gastos, o sea... yo le mando para que mi mamá cocine un poquito más para mis hijos... y mis papá los sostiene, mi papá los lleva al jardín... (risas) al jardín ¿qué estoy hablando?... al colegio... estoy pensando en mi niño chiquitito... al colegio a los dos, y los lleva y los recoge.

Al contrario, el caso de un abuelo que no aporta en el cuidado:

A ver ¿cuéntame? Fui y estábamos escuchando música o estamos viendo una película... y ¿ por qué no lo invitas a la casa?... no, porque mi papá Lucho (abuelo) se enoja...

24 Si Somos Americanos. Revista de Estudios Transfronterizos 
entonces es como, o sea mi papá se enoja, porque mi papá no entiende las cosas de ahora, obviamente. Entonces, se enoja por eso... no quiere llevar a la casa los amigos.

Es posible que el padre tenga alguna responsabilidad en la práctica, como también en la crianza de los niños a distancia, sin embargo, es relevante destacar que en ningún caso las mujeres destacan sus roles ni le otorgan importancia, como tampoco les resta la culpa o responsabilidad por "dejar a sus hijos". Más bien, hay casos donde el hombre culpa a las madres por el embarazo de sus hijas, por dejarlas en Perú y por fracasos en el colegio.

Es en ese continuo dilema que opera la posibilidad de transformación o permanencias de determinas prácticas de género y parentesco, así como los significados que conllevan (Gonzálvez, 2007). La situación transnacional a la que se enfrenta la familia sí puede conllevar cambios en los roles femeninos para las mujeres. Ante la perspectiva del regreso del esposo, en algunos casos la mujer percibe la recomposición de las relaciones de pareja desde la proximidad y el contacto diario como un proceso complicado; por cuanto se asume que el período de separación le ha permitido a ella ganar autonomía y libertad de movimiento (Parella, 2012, p. 674).

Estos cambios son fugaces y drásticos, un caso es refugiarse en el trabajo e intentar olvidarse durante la jornada laboral. Este es el caso de una entrevistada que desde que llegó a Chile se ha dedicado a trabajar; al comienzo, de domingo a domingo, y luego, cuando se trajo a su hija, continúa haciéndolo más allá de su jornada. Ella incluso está consciente de que es una de las razones por las que dejó a su hija sola aquí:

Sí, cuando mi hija quedó embarazada fue terrible, era terrible para mí porque yo estaba sola, y yo la había traído para acá y decir qué me hago con mi hija embrazada, fue terrible, que, que yo sabía, no tenía, no pensaba... o yo que siempre escucho decir a las personas que la hija salió embarazada y que había tenido que hacerse cargo la mamá con el hijo y todo eso... y eso me preocupaba, pero igual empezó a ayudar este chico, igual no la dejó sola... Me hubiera gustado que... no sé, que... ella se hubiera quedado quizás mejor allá, le hubiera ido mejor, si se hubiera quedado en el país le hubiera ido mejor, porque ahí está mi mamá, mi papá ahí con ella, y yo para que esté conmigo me la traje e igual fue malo, porque yo por estar trabajando, me la descuidé mucho.

Ahora bien, a pesar de sobrellevar la pena en la jornada laboral, ellas expresan que rápidamente vuelven a la nostalgia al llegar a sus hogares. Este es el caso de una mujer que trabaja puertas adentro y explica que durante el día tiene mucha actividad, por lo que está 
muy tranquila. Sin embargo, comenta que apenas llega a su pieza, comienza a recordar, incluso el único día libre que arrienda una pieza, los domingos, los pasa con una amiga que está en su misma situación:

Alquilamos una piecita... nos compramos una cama y después nos compramos un par de sabanitas, porque pensamos que no vamos a estar toda la vida acá, entonces nos quisimos comprar lo más cómodo que sea, porque la cosa es ahorrar... entonces compramos lo más cómodo una cama, una cocinita, una televisión, frazadas porque nos morimos de frió y el calentadorcito, y así, lo esencial... y a nosotros llegamos a la casa... depende de la hora que lleguemos, si llegamos nosotras tarde una oncecita... tomamos, conversamos... de nuestras vidas, cómo lo pasábamos allá y todo recordando todo... hablamos de nuestros hijos, porque ella también tiene allá... y prendemos la televisión, escuchamos música peruana... ya después de todo nos dormimos, ya es domingo, después tomamos desayuno, ella de repente... a mí me toca preparar el desayuno, yo preparo... pancito con algo comemos... lavamos los servicios... y luego vamos a la feria a comprar algo para cocinar... y cocinamos y ya, después de almorzar y todo se hace tarde... y al trabajo cada una.

También pueden evitar la tristeza con parte de su familia en Chile, pero esto les recuerda constantemente quiénes están allá. Este es el caso de una mujer que primero trajo a su marido a Chile y tuvo a sus hijos con su hermana. Ella comenta que ese año el matrimonio no lo podía pasar bien, pues constantemente recordaban a sus hijos:

Muy duro, no lo podíamos pasar bien, claro yo en el trabajo... igual con la impotencia de haberlos dejado allá, la pena, mi marido se quería regresar, fue algo súper duro, pero como digo... sufrimos, pero después lo fuimos a traer.

Lo anterior se traduce en constantes cambios de ánimo que las hacen pasar de la alegría a la pena rápidamente, y viceversa. Situaciones, como conversar o enterarse de problemas con su familia en Perú, les pueden cambiar radicalmente el ánimo, y por otro lado, tampoco les permite pasar buenos momentos en Chile.

Esto, igualmente, se extiende en el caso de las mujeres que ya llevan más de 10 años en Chile y que se han acostumbrado al país. Ellas se han adaptado a la ciudad, al trabajo y también a su situación aquí:

Acá, aquí o sea... en este minuto no paso las noches en mi casa, paso el día, paso el día en mi casa, pero por eso más que todo es por un tema de trabajo... ya yo me he

\section{Si Somos Americanos. Revista de Estudios Transfronterizos}


acostumbrado al ritmo de acá, tú te sientes cómoda acá... es difícil, porque por un tema de trabajo yo me siento más cómoda acá, allá están mis papás y mi hijo que me une allá.

Lo que tienen en común todas estas situaciones, es que la reorganización de la familia y de la vida cotidiana es un asunto de mujeres.

\section{La culpa/liberación por el cuidado}

La separación es el primer hito importante para una mujer madre, no solo por sus efectos emocionales, sino también porque requiere una reorganización del cuidado por parte de sus familiares cercanos. Aquí encontramos una gran variedad de situaciones y distintos grados de vulnerabilidad que tienen que ver nuevamente con la construcción social del género; con la densidad de la red familiar que se ha quedado a cargo y su capacidad para asumir múltiples funciones relativas al cuidado; con el grado de comunicación de la madres con sus familiares en origen y, especialmente, con sus hijos; $y$, finalmente, con la capacidad de la madre de asegurar la reproducción económica de su familia, es decir, de cumplir el rol de proveedora.

El cuidado se despliega y reorganiza entre abuelas, tías, hermanas mayores. Los niveles de participación de los padres son diversos, pero invariablemente participan mujeres. Nuevamente entra en juego una visión tradicional del cuidado como una actividad a cargo de las mujeres, visión que es reproducida por las propias madres migrantes, quienes se sienten en algunos casos más seguras de que sus hijos queden a cargo de los abuelos/as (Herrera y Carrillo, 2009, pp. 41-42).

Además del recurso de las abuelas, es cada vez más habitual contratar formal o informalmente a otra mujer en el país de origen para que se haga cargo de los hijos de la mujer que emigra, a cambio de un salario mucho más bajo que el percibido por la emigrante en la sociedad receptora, como también se ven casos donde la mujer emigrante no tiene los recursos económicos y encarga sus hijos a otra mujer por un mínimo monto de dinero informalmente. Así se constituyen las "cadenas mundiales de afecto y asistencia", integradas por distintos vínculos y grados, a escala global, y basadas en el trabajo de cuidado remunerado y no remunerado (Parella, 2007, p. 163).

Uno de los aspectos que mejor permite entender cómo se manejan los vínculos transnacionales a través de la distancia, es la comunicación, tanto entre el migrante y 
sus hijos como entre este y el cuidador. Además, permite establecer el tipo de vínculo que se elabora entre unos y otros, al tiempo que visibiliza cómo se ha transformado la relación. En este sentido, las Tecnologías de la Información y la Comunicación (TICs) se han convertido en las principales herramientas que permiten sostener nuevas formas de relaciones sociales, que facilitan a las familias transnacionales mantener y gestionar de manera efectiva sus vínculos afectivos y de cuidado, logrando, además, que los migrantes se apropien de estas tecnologías y logren con ello mitigar los impactos que podría desencadenar la separación física.

Las entrevistas realizadas muestran cómo a través de la utilización de las TICs como las llamadas telefónicas, las videoconferencias, los correos electrónicos, las redes sociales en internet, entre otras- se puede intercambiar todo tipo de emociones, expresiones de afecto, autoridad y cuidado que giran en torno a un interés común y circunstancias compartidas. Incluso, algunas familias han intentado realizar actividades cotidianas a través de las TICs, tales como escuchar una misma estación de radio, ver simultáneamente una película, o seguir una misma serie o telenovela; estrategias que les permiten generar un discurso conjunto cargado de significado grupal que acorta la distancia entre ellos.

La novedad de la migración sur-sur es que permite prácticas de ir y volver, por lo que la relación madre/padre-hijo es, al menos, más frecuente que una relación donde hay aún más distancia geográfica. De esta manera, los encuentros esporádicos son especialmente necesarios para recrear el vínculo entre padres e hijos o el de pareja, bien sea que el migrante viaje a Perú o que sus hijos y cónyuge viajen a Chile.

Las mujeres entrevistadas comentan en sus relatos cómo han organizado su vida en Chile desde que llegaron solas. Uno de los principales apoyos ha sido construir lazos con otras personas, especialmente otras mujeres, al menos es así como ellas lo expresan. Lo anterior, puesto que más allá del círculo familiar - la mayoría tiene parejas y claramente el apoyo de su familia- las entrevistadas construyen lazos emocionales y funcionales con otras mujeres en Chile y en Perú para sobrellevar su situación en Chile.

Establecen lazos funcionales, pues les sirven para mantener y reconstruir a sus familias, contribuyendo a tener el máximo control de los eventos y situaciones que suceden en Perú y Chile mientras ellas no están. Funcionales, en el sentido que le sirven para cubrir aspectos prácticos y cotidianos de su familia: cuidado, colegio, salud. 
También construyen lazos emocionales, en la medida que les permiten hacer más llevadero la situación de estar solas o con parte de su familia en otro país. Lazos que mayoritariamente reemplazan los vínculos de parentesco y que pasan a ser un apoyo fundamental concebido como "familia en Chile". Estas relaciones les ayudan a cubrir su soledad y vacíos emocionales producidos por el tiempo en Chile.

Ejemplo de aquello es una entrevistada que generó un lazo muy fuerte con su compañera de cuarto, con quien comparte solo el domingo y algunos sábados, detallando experiencias con sus hijos, pues está en la misma situación que ella:

Porque como ves, yo comparto como si fuera una familia de verdad, cuando tengo una necesidad ellos me ayudan, no necesariamente una necesidad económica, sino el cariño y el respeto... porque uno aquí se siente tan sola, que el dinero no te llena, te llena una sonrisa, que te abran las puertas, que te dice oye, sírvete un vaso de agua, una sonrisa que te dan... porque piensas en compartir con otra persona que no te quiere, o que les estorbas, que porque no llega la noche y tengo que dormir con esta persona, no es tu casa, no es tu cama.

Un lazo funcional, por ejemplo, es el caso de una mujer que conoció a una chilena, quien le ayudó con los niños mientras trabajaba:

Entonces, buscamos a una señora que era demasiado buena y ella veía a mis niños... entonces, también tuve que dejarlos cuando me iba a trabajar... en el momento que llegaban del colegio los veía... y me decía que no me preocupaba, que no iban a estar solos... Ella es chilena... entonces ella, pendiente de los niños, los iba a mirar que no vayan a prender fuego entonces, arrendábamos.

Otro caso es el de la cuidadora de una entrevistada, una mujer que no es parte de su familia, pero que le ayuda con su hijo, también a la distancia:

Ella como que juega un papel importante en la casa... porque ella los lleva al doctor, porque después cuando regresa y me dice todo lo que le dice el médico, y va a las reuniones del colegio, de mi hijo, a preguntar ¿cómo le va en el colegio? Y eso, si le falta, po' ejemplo a parte si pregunta conversa... es muy cercana ella a él, le pregunta de hecho... a ¿dónde vas a salir tú?... voy a salir con mi amiga, señora Tere... voy a salir a con una amiga... y le dice... dígale a mi mamá (mi mamá le dice a mi mamá) que me deje salir... olvídalo, tú te sales y no haces caso, yo llego a tal hora... pero nada más. 
Tanto el estudio de Herrera y Carrillo (2005) como el de Camacho y Hernández (2005) argumentan que cuando los hijos se han quedado con su papá, generalmente hay un grupo de mujeres a su alrededor que apoyan en las tareas de cuidado.

Este soporte puede significar desde ayudas puntuales en el cuidado o la alimentación diaria, hasta el hecho de que eventualmente los/as niños/as vivan con sus abuelas y visiten a su padre los fines de semana. En ese sentido, se crea cierta dispersión que tiene varias consecuencias: por un lado, los jóvenes no tienen claro cuál es el verdadero referente de autoridad; por otro lado, la madre ausente sigue muy presente y dirime en caso de conflictos. En consecuencia, la reorganización del cuidado involucra a varios actores, como en ausencia de la madre el cuidado se reparte entre varios, incluidos los propios jóvenes frente sus hermanos (Herrera y Carrillo, 2009).

En realidad, el contexto transnacional y los cuidados transnacionales en manos de las mujeres son vehículos por medio de los cuales los padres, y algunos familiares de la migrante - como la madre o la hermana-imponen el sentimiento de culpa en estas mujeres en tanto madres, cuando no cumplen con su mandato de género parentesco tradicional. Por este motivo, ya sea como algo impuesto, o producto de una elección, las mujeres vuelven para cuidar a sus hijos cuando están lejos - cuidado personal一, envían remesas de forma sacrificada - cuidado transnacional-, llaman de forma constante a origen - trabajo de parentesco transnacional-. Por el contrario, los cuidados transnacionales pueden llegar a ser prácticas de cuidado por donde circula también el reconocimiento, la gratificación (hijos/as, familia, etc.), por la posibilidad de recibirlos por parte de los familiares que están en origen, lo cual, en algunas mujeres, provoca nuevas socializaciones, nuevas formas de pertenecer (Gonzálvez, 2007).

Es posible examinar en los relatos, una constante contradicción emocional en las mujeres. Ellas comentan que experimentan muy seguido cambios de ánimo, desde estar muy contentas con su vida acá, hasta sentir mucha culpa y pena por la situación en Perú. Hay algunos eventos que hacen que ellas se olviden de su situación con la familia en su país, por ejemplo, en el trabajo, con los amigos y parte de su familia acá que las mantienen ocupadas y contentas. Sin embargo, rápidamente las embarga la tristeza de no poder compartir estas situaciones con su familia. 


\section{La restructuración de las relaciones de poder en la familia transnacional}

No obstante, como era de esperar, es ante la emigración femenina pionera donde se han identificado mayores impactos en los roles familiares de género. Los trabajos de Salazar (2005) ponen de manifiesto, para el caso filipino, que las estructuras familiares transnacionales conllevan contradicciones de género. La emigración femenina genera fisuras en torno al papel tradicional de la esposa y madre (Parella, 2012, p. 674).

La mujer, por lo general, debe hacer frente al dolor, por la separación, y a la estigmatización social, por no estar junto a sus hijos. La estigmatización social está focalizada en la ausencia femenina: hay discursos que atribuyen bajo desempeño escolar, depresión, embarazos de los hijos a la emigración femenina.

Para las mujeres que han emigrado, se percibe el logro de prestigio no tanto a partir del tipo de inserción socioeconómica lograda, sino sobre la base de poder ejercer de principales sustentadoras del grupo familiar. Se trata de un discurso que combina el logro económico para sus familiares con una forma activa de construcción de su propia "emancipación", utilizando la competencia adquirida a través de la migración (Parella, 2012, p. 674).

Sin embargo, los trabajos de Salazar (2005, p. 332) evidencian cómo las contribuciones económicas de las mujeres filipinas que habían emigrado a los Estados Unidos no implican una reconfiguración de la división sexual del trabajo dentro de la familia. Los hombres, raramente, se ocupan del trabajo doméstico y familiar. De hecho, se argumenta que cuando es la mujer la que emigra, se asiste a un incremento de la implicación del varón en las tareas reproductivas, aunque siempre en calidad "de apoyo" a otras mujeres de la familia, generalmente las "suegras". De ese modo, o bien son las abuelas las que se trasladan al hogar familiar, o bien son los/as hijos/as y el esposo los que se instalan en la vivienda de sus suegros o de sus padres (Parella, 2012, p. 677).

\section{Conclusiones}

Más allá de las experiencias migratorias en general y sus consecuencias en la familia, para las mujeres entrevistadas, su migración ha significado grandes aprendizajes. Efectivamente, les ha permitido valorar más a su familia y la vida que tenían en Perú, como uno de los mayores aprendizajes de la migración de estas mujeres; asimismo, va- 
lorar lo que tenían en su país, respecto a la familia, pero también a la seguridad que les entrega el entorno. Sin embargo, los relatos muestran que ellas han logrado aprender en distintos niveles. En el nivel familiar, claramente han aprendido a valorar a sus hijos, a sus padres, a tener a la familia como prioridad.

En la mayoría de los casos, no habían salido ni siquiera de su ciudad y menos solas, por lo que la migración no es solo un método para mejorar la condición socioeconómica mediante el trabajo en otro país, sino también se transformó en una enorme fuente de conocimientos: han aprendido a manejarse solas en otro país, lo que implica manejar otro idioma, lenguaje, otro tipo de relaciones sociales, prácticas, cultura, idiosincrasia. Todo lo anterior sumado a que están en desventaja por la discriminación y segregación que hay hacia peruanos y peruanas en Chile.

La migración también les ha permitido aprender a establecer redes laborales y generar lazos con personas desconocidas, desde personas en el aeropuerto para cuidar sus pertenencias hasta redes de amigos/as para cambiar de trabajo y comprar una casa. Además, explican que las ha sacado del círculo protegido de su familia, logrando aprender a vivir sin compañía, y hacer estrategias de sobrevivencia, por ejemplo, cuando se han quedado sin trabajo estando solas en el país.

Lo anterior les ha permitido valorarse a sí mismas y, como mujeres, salir de su país a trabajar en un lugar con personas desconocidas, armar redes y generar lazos, desarrollar estrategias para el más eficiente sustento económico, como también haber pasado por mucha tristeza y, sin embargo, mantenerse de pie, traer a parte de su familia al país receptor, mantener un trabajo a pesar de las circunstancias, acostumbrarse a un lugar muy reacio a la comunidad peruana en general y, finalmente, construir una familia en Chile y mantener a su familia en Perú; estos son algunos de los aprendizajes más importantes para ellas.

Lo anterior se traduce en lo que una de las mujeres explica; a pesar del poco tiempo viviendo en Chile, comenta:

Con mi familia, bueno... mi familia me respeta más, me valora más, como que me extrañan... bastante cuando estoy allá, me consideran más... era machista... pero la mayoría es machista, lo que ellos dicen se hace y yo estaba acostumbrada a eso... si tenía razón o no... y yo me quedaba llorando y llorar y aceptar... pero no, ya aprendí acá, porque uno aprende bastante, a respetarte a mí misma, a valorista a sí misma, a quererte a a... y ahora a mi marido yo mando... que me dice que terminemos y esto...

\section{Si Somos Americanos. Revista de Estudios Transfronterizos}


ya po' terminamos. Pero a mí no me gritas, y de abandonarme... a él le ha afectado bastante... o "la china cambió, ha crecido" dice. Y no es eso, es quererse más también.

Las entrevistadas explican que su experiencia les ha permitido crecer como madres, hijas y también como mujeres, se valoran más a sí mismas y consideran que ellas tienen el control de sus vidas, lo que no era posible cuando estaban en Perú. Más allá de ser proveedoras de su familia, también consideran que esto es consecuencia de la migración y de lo que les obliga a aprender, y a generar estrategias de sobrevivencia útiles no solo para ellas como madres e hijas, sino también como mujeres.

Las mujeres entrevistadas han aprendido a sobrellevar la distancia mediante el uso de prácticas a distancia, que les permiten tener el control casi absoluto de sus familias en Perú, además de la que tiene en Chile. Han generado distintos tipos de lazos y redes de apoyo, como también estrategias para reconstruir su familia luego de la separación.

Efectivamente, las mujeres desempeñan un papel clave en el mantenimiento de los lazos familiares, a pesar de la distancia física que separa a sus miembros (Baby-Collins, Cortes y Sassone, 2008; Zontini, 2010). Cuando ellas emigran, además de la función económica y productiva que asumen (envío de remesas), son las principales articuladoras de los espacios sociales transnacionales a través de su trabajo reproductivo cotidiano (Pedone, 2004). Las mujeres son centrales en la organización socio-espacial de la migración y, en definitiva, en la asunción de los distintos rituales de socialización, a fin de mantener la cohesión del grupo familiar (Alicea, 1999; Pedone, 2004).

La emigración de las mujeres transforma, reorienta e impacta en los/as hijos/as que permanecen en origen en mayor medida que la masculina. Así se confirma para los resultados de nuestro trabajo de campo. Los efectos negativos ante la ausencia de la madre son mencionados de forma explícita por algunos relatos y están estrechamente vinculados a la edad de los/as hijos/as durante el período de separación (Parella, 2012, p. 677). Los efectos oscilan desde un descenso del rendimiento académico, depresión y embarazos adolescentes de las hijas.

La capacidad de la madre de mantener el contacto desde la distancia es fundamental a la hora de modular los efectos de la separación, aunque no siempre es suficiente para compensar estas funciones afectivas que el padre no se ve capaz de asumir, como tampoco las funciones principales de la crianza y cuidado de los/as hijos/as, más allá de lo básico (tareas escolares y cuidado de la salud). 
La familia transnacional es, entonces, una unidad de análisis para el abordaje académico de las dinámicas migratorias y de las reconfiguraciones de las relaciones de género e inter generacionales que de ellas se derivan. Desde una perspectiva de género, esta forma de organización social no solo permite captar las transferencias económicas familiares y la gestión y los impactos de las mismas, también permite escatimar la gestión de la reproducción social: afectos, emociones, cuidado, reparto de funciones, comunicación, etc.

Al focalizarnos en las prácticas y redes que las mujeres establecen, más allá de las remesas, es posible conocer la construcción simbólica de unidad de los integrantes de las familias extensas. Las redes migratorias conectan a los migrantes en tiempos y espacios, estableciendo espacios plurilocales que permiten el intercambio y circulación de bienes materiales, culturales y simbólicos, con el objetivo de mantener y reproducir el grupo familia.

Las familias transnacionales exigen una reacomodación permanente de las relaciones de género y generacionales en cuanto a los vínculos económicos, afectivos y de poder dentro del grupo doméstico, tanto en los lugares de origen como de destino (Pedone, 2008). Tales articulaciones están fuertemente condicionadas por el género. Las mujeres desempeñan un papel clave en dichos procesos, por cuanto son el elemento central para el mantenimiento de los lazos familiares, como también constituyen el "nodo intergeneracional" que permite mantener la cohesión del grupo familiar y las redes migratorias (Baby-Collins et al., 2008).

Para el caso específico de las transformaciones en las relaciones de género desde la perspectiva de las mujeres, sus experiencias en los procesos migratorios pueden ser muy diferentes y oscilan desde el empoderamiento hasta la pérdida de estatus social (Magliano, 2007). Un factor determinante en el significado "emancipador" o de "empoderamiento" de la migración es la inserción laboral que tengan en el país de destino.

Se logró revisar que, de acuerdo a la definición de Bryceson y Vuorela (2000), la familia transnacional es "aquella familia que vive buena parte o la mayor parte del tiempo separada. Sin embargo, a pesar de la distancia, ésta logra mantenerse unida dando paso a un sentimiento colectivo de bienestar y de unidad que supera las fronteras nacionales" ( $\mathrm{p}$. 3). Es decir, el análisis de la familia transnacional provee evidencias de que la reproducción social es capaz de traspasar las fronteras del Estado-nación para perpetuarla (Levitt y Glick Schiller, 2004). 
La reorganización de la familia se modifica con la migración a través de las prácticas y vínculos desde el país de origen y de destino, se modifican los significados de la experiencia individual, y también cambia la estructura familiar. Se puede concluir que, efectivamente, es la mujer la responsable de activar y mantener las prácticas y vínculos con su familia. La familia, paralelamente, debe hacer arreglos para reacomodarse a la situación y utiliza estrategias para que la separación no sea tan compleja. Asimismo, integra nuevos participantes para colaborar con la misma.

\section{Referencias}

Alicea, M. (1999). A Chambered Nautilus: The Contradictory Nature of Puerto Rican Women's Role in the Social Construction of a Transnational Community. Gender and Society II (5), 597-626.

Ariza, M. (2000). Ya no soy la que dejé atrás...: Mujeres migrantes en República Dominicana. México: Plaza y Valdés.

Baby-Collins, V., Cortes, G., y Sassone, S. (2008). Mujer, movilidad y territorialización: Análisis cruzado de las migraciones internacionales en México y Bolivia. En H. Godard y G. Sandoval (eds.), Migración transnacional de los Andes a Europa y Estados Unidos (pp. 135-166). Lima, Perú-La Paz, Bolivia: IFEA/PIEB/IRD.

Bryceson, D.F., y Vuorela, U. (2002). Transnational Families in the Twenty-first Century. En D. F. Bryceson, y U. Vuorela (eds.), The transnational Family: New European Frontiers and Global Networks (pp. 3-30). Oxford, UK: Berg Publishers.

Cacopardo, M. C., y Maguid, A. (2003). Migrantes limítrofes y desigualdad de género en el mercado laboral del Área Metropolitana de Buenos Aires. Desarrollo Económico 43 (170), 265-286.

Camacho, G., y Hernández, K. (2005). Cambio en mi vida: migración femenina, percepciones e impactos. (Investigación Técnica). Quito, Ecuador: UNIFEM, CEPAES.

Cano, V., Contrucci, M., y Martínez, J. (2009). Conocer para legislar y hacer política: Los desafíos de Chile ante un nuevo escenario migratorio. Población y Desarrollo 88. Santiago, Chile: CEPAL. 
Denzin, N., y Lincoln, Y. (2005). The Sage Handbook of Qualitative Research. Third Edition. London, UK: Sage Publications.

Doña, C., y Amanda, L. (1 de febrero de 2004). Chile: moving towards a migration policy. Migration Information Source, Migration Policy Institute (MPI). Consultado el 19 de mayo de 2008 en http://www.migrationpolicy.org/article/chile-moving-towards-migration-policy.

Faist, T. (2000). Transnationalization in international migration: implications for the study of citizenship and culture. Ethnic and Racial Studies 23 (2), 189-222.

Glick Schiller, N., Basch, L., y Szanton-Blanc, C. (1992). Towards a Definition of Transnationalism: Introductory Remarks and Research Questions. Annals of the New York Academy of Sciences 645, IX-XIV.

Gonzálvez, H. (2007). Familias y hogares transnacionales: Una perspectiva de género. Puntos de Vista. Cuadernos del Observatorio de las Migraciones y de la Convivencia Intercultural de la Ciudad de Madrid 10 (III), 7-27.

Gregorio, C. (1998). Migración femenina. Impacto en las relaciones de género. Madrid, España: Narcea.

Guarnizo, L. (1997). Going Home: Class, Gender and Household Transformation Among Dominican Return Migrants. Caribbean Circuits: New Directions in the Study of Caribbean Migration 13 (4), 13-60.

Guarnizo, L., Portes, A., y Haller, W. (2003). Assimilation and Transnationalism: Determinants of Transnational Political Action among Contemporary Immigrants. American Journal of Sociology 108 (6), 1211-1248.

Herrera, G. (2004). Elementos para una comprensión de las familias transnacionales desde la experiencia migratoria del Sur del Ecuador. En F. Hidalgo (ed.), Migraciones: Un juego con cartas marcadas (pp. 215-233). Quito, Ecuador: ILDIS, Abya Yala.

Herrera, G. (2005). Mujeres ecuatorianas en las cadenas globales del cuidado. En G. Herrera, C. Carrillo y A. Torres (eds.), Migración ecuatoriana: Redes, transnacionalismo e identidades (pp. 281-303). Quito, Ecuador: FLACSO, Plan Migración Comunicación y Desarrollo.

36 Si Somos Americanos. Revista de Estudios Transfronterizos 
Herrera, G. (2011). Cuidados globalizados y desigualdad social. Reflexiones sobre la feminización de la migración andina. Revista Nueva Sociedad 233, 87-97.

Herrera, G., y Carrillo M. (2005). Los hijos de la migración en Quito y Guayaquil. Familia, reproducción social y globalización. En G. Solfrini (ed.), Tendencias y efectos de la migración en el Ecuador, Vol. 3 (pp.11-80). Quito, Ecuador: Alisei.

Hondagneu-Sotelo, P. (2000). The international Division of Caring and Cleaning Work. En M. Harrington (ed.), Care Work, Gender Labor and Welfare State (pp. 423-451). New York: Routledge.

Hondagneu-Sotelo, P. (2007). Doméstica: Immigrant Workers Cleaning and Caring in the Shadows of Affluence, with a New Preface. 2nd. ed. Berkeley, Estados Unidos: University of California Press (Spanish language translation, México, Miguel Ángel Porrúa, forthcoming 2011).

Lamas, M. (2003a). La antropología feminista y la categoría género. En M. Lamas (comp.), $E l$ género. La construcción cultural de la diferencia sexual (pp. 97-125). México: Universidad Nacional Autónoma de México.

Lamas, M. (2003b). Usos, dificultades y posibilidades de la categoría género. En M. Lamas (comp.), La construcción cultural de la diferencia sexual (pp. 337-366). México: Universidad Autónoma de México.

Le Gall, J. (2005). Familles transnationales: bilan des recherches et nouvelles perspectives. Diversité urbaine 5 (1), 29-42.

Levitt, P., y Glick-Schiller, N. (2004). Conceptualizing Simultaneity: A Transnational Social Field Perspective on Society. The International Migration Review 38 (3), 1002-1039.

López, S., y Acosta A. (2003). Causas del reciente proceso emigratorio ecuatoriano. Cartillas sobre Migración. Plan Migración, Comunicación y Desarrollo 3. Recuperado en http:// www.fes-ecuador.org/media/pdf/migracion3.pdf

Magliano, M. J. (2007). Migración de mujeres bolivianas hacia Argentina: Cambios y continuidades en las relaciones de género. Amérique Latine Histoire et Mémoire. Les Cahiers ALHIM [en línea], 14. Recuperado en http://alhim.revues.org/index2102.html.

Mahler, S.J., y Pessar, P. (2006). Gender Matters: Ethnographers Bring Gender from the Periphery toward the Core of Migration Studies. International Migration Review 40 (1), 27-63. 
Martínez, J. (2003). El mapa migratorio de América Latina y el Caribe, las mujeres y el género. Serie Población y desarrollo 44 (LC/L.1974-P). Santiago de Chile, Comisión Económica para América Latina y el Caribe (CEPAL): Publicación de las Naciones Unidas.

Massey, D. et al. (1993). Theories of International Migration: A Review and Appraisal. Population and Development Review 19 (3), 431-436.

Moore, H. (1999). Antropología y feminismo. Madrid, España: Cátedra.

Mora, C. (2008). Globalización, género y migración. Polis 7 (20), 285-297.

OIM. (2006). La OIM y la migración laboral. Ginebra, Suiza: OIM.

ONU. (2006). Estado de la población mundial 2006. Hacia la esperanza: las mujeres y la migración internacional. Nueva York, Estados Unidos: ONU/UNFA.

Oso, L. (2007). Migración, género y hogares transnacionales. En V Congreso de la Inmigración en España. Valencia, España.

Parella, S. (2007). Los vínculos afectivos y de cuidado en las familias transnacionales: Migrantes ecuatorianos y peruanos en España. Migraciones Internacionales 4 (2), 151-188.

Parella, S. (2012). Familia transnacional y redefinición de los roles de género. El caso de la migración boliviana en España. Papers 97 (3), 661-684.

Pedone, C. (noviembre 2004). Negociaciones en torno al asentamiento definitivo de las familias migrantes ecuatorianas: Construcción de espacios sociales transnacionales. En 40 Congreso sobre la Inmigración en España. Girona, España.

Pedone, C. (2008). Varones aventureros vs. Madres que abandonan. Reconstrucción de las relaciones familiares a partir de la migración ecuatoriana. REMHU. Revista Interdisciplinar da Movilidade Humana 30, 45-64.

Reist, D., y Riaño, Y. (2008). Hablando de aquí y de allá: patrones de comunicación transnacional entre migrantes y sus familiares. En G. Herrera y J. Ramírez (eds.), América Latina migrante: Estado, familia, identidades (pp. 303-323). Quito, Ecuador: FLACSO.

38 Si Somos Americanos. Revista de Estudios Transfronterizos 
Rico, N. (junio 2006). Las Mujeres Latinoamericanas en la Migración Internacional. En Seminario: Las mujeres trabajadoras inmigrantes y sus aportes al desarrollo del país de acogida y de origen. Madrid, España.

Rivas, A. M., y Gonzálvez, H. (eds.). (2009). Familias transnacionales colombianas: Transformaciones y permanencias en las relaciones familiares y de género. Madrid, España: Catarata.

Rosas, C. (2010). Implicaciones mutuas entre el género y la migración. Mujeres y varones peruanos arribados a Buenos Aires entre 1990 y 2003. Buenos Aires, Argentina: Editorial Universitaria de Buenos Aires, EUDEBA.

Salazar, R. (2005). Long distance intimacy: class, gender and intergenerational relations between mothers and children in Filipino transnational families. Global Networks 5 (4), 317-336.

Stefoni, C. (2007). La migración en la agenda chileno-peruana. Un camino por construir. En M. Artaza y P. Milet, Nuestros vecinos (pp. 551-64). Santiago, Chile: RIL Editores, Universidad de Chile.

Stefoni, C. (2009). Inmigrantes en Chile. Una integración diferenciada al mercado laboral. En Sopla, Migración y políticas sociales en América Latina (pp. 81-108). Río de Janeiro, Brasil: Konrad Adenauer Stiftung.

Tapia, M. (2010). Inmigración boliviana en España. Un caso para la comprensión de la migración internacional con perspectiva de género. Revista Boliviana de Ciencias Sociales T'inkazos 28, 109-127.

Vertovec, S. (2004). Migrant Transnationalism and modes of transformation. International Migration review 38 (3), 970-1001.

Zontini, E. (2010). Transnational families, migration and gender: Moroccan and Filipino women in Bologna and Barcelona. Oxford, UK: Berghahn Books. 


\section{Anexo}

TABLA1

Resumen de Casos

\begin{tabular}{|c|c|c|c|c|}
\hline & Mujer 1 & Mujer 2 & Mujer 3 & Mujer 4 \\
\hline Edad & 42 años & 43 años & 41 años & 50 años \\
\hline $\begin{array}{l}\text { Trabajo } \\
\text { Actual }\end{array}$ & $\begin{array}{l}\text { Empleada } \\
\text { doméstica puertas } \\
\text { adentro }\end{array}$ & $\begin{array}{l}\text { Empleada } \\
\text { doméstica por día } \\
\text { puertas afuera }\end{array}$ & $\begin{array}{l}\text { Cuidado de adulto } \\
\text { mayor }\end{array}$ & $\begin{array}{l}\text { Dueña de una } \\
\text { peluquería }\end{array}$ \\
\hline Estudios & Técnico de chef & Primaria completa & $\begin{array}{l}\text { Técnico en } \\
\text { enfermería }\end{array}$ & $\begin{array}{l}\text { Secundaria } \\
\text { completa }\end{array}$ \\
\hline $\begin{array}{l}\text { Años en } \\
\text { Chile }\end{array}$ & 3 años & 11 años & 5 años & 12 años \\
\hline $\begin{array}{l}\text { Motivo } \\
\text { migración }\end{array}$ & $\begin{array}{l}\text { Mala situación } \\
\text { económica }\end{array}$ & $\begin{array}{l}\text { Mala situación } \\
\text { económica }\end{array}$ & $\begin{array}{l}\text { Sin posibilidad de } \\
\text { encontrar trabajo }\end{array}$ & $\begin{array}{l}\text { Sin posibilidad de } \\
\text { encontrar trabajo }\end{array}$ \\
\hline Hijos & $\begin{array}{l}2 \text { hijos de } 9 \text { y } 8 \\
\text { años peruanos }\end{array}$ & $\begin{array}{l}\text { Una hija de } 17 \\
\text { años y un hijo de } \\
14 \text { años peruanos }\end{array}$ & $\begin{array}{l}\text { Un hijo de } 4 \text { años } \\
\text { chileno y un hijo } \\
\text { de } 17 \text { años peruano }\end{array}$ & $\begin{array}{l}\text { Un hijo de } 27 \text { años } \\
\text { peruano y una hija } \\
\text { de } 23 \text { años peruana }\end{array}$ \\
\hline Pareja & $\begin{array}{l}\text { Peruano vive en } \\
\text { Perú }\end{array}$ & $\begin{array}{l}\text { Peruano vive en } \\
\text { Chile }\end{array}$ & $\begin{array}{l}\text { Peruano vive en } \\
\text { Chile }\end{array}$ & $\begin{array}{l}\text { Separada vive en } \\
\text { Perú }\end{array}$ \\
\hline $\begin{array}{l}\text { Familia en } \\
\text { Perú }\end{array}$ & Completa & $\begin{array}{l}\text { Una hermana y } \\
\text { familia del marido }\end{array}$ & $\begin{array}{l}1 \text { hijo de } 17 \\
\text { años, sus papás y } \\
\text { hermanos }\end{array}$ & $\begin{array}{l}1 \text { hijo de } 27 \\
\text { años, sus papás y } \\
\text { hermanos }\end{array}$ \\
\hline
\end{tabular}

Fuente: elaboración propia 